\title{
Pelatihan Keterampilan Membuat Informasi Berbasis Video Digital Pada Ikatan Remaja Masjid
}

\author{
Loneli Costaner*1, Guntoro² $^{2}$ Lisnawita $^{3}$ \\ 1,2,3Program Studi Teknik Informatika, Fakultas Ilmu Komputer, Universitas Lancang Kuning \\ *e-mail: lonelicostaner@gmail.com ${ }^{1}$,guntoro@unilak.ac.id ${ }^{2}$,lisnawita@unilak.ac.id³
}

\begin{abstract}
Activities in mosques are not only carrying out ritual worship activities, more than that mosques can also print young generations to grow the spirit of organization and creativity. One way to foster the spirit of youth organization is the existence of the Mosque Youth Association (IRMAS). Every IRMAS activity will always prepare information, both for event information and useful information to attract the attention of the public, youth and youth to gain knowledge, the information provided can also be a means of da'wah by optimizing on Instagram and YouTube social media. The problems and obstacles for partners are that they do not yet have the ability to create digital video-based information, both for making community profiles, story activities and media promotion of IRMAS activities as well as interesting da'wah facilities so that social media cannot be improved properly. So the solution that can be done is to train partners' skills in making digital video-based information with the kine master android application and training to optimize their social media as a means of information, promotion and da'wah. The method used in this training is lecture and practice, where training participants will be given an understanding of digital video-based information, how to create digital videobased information and applications used to create digital information, such as text processing, image processing, video processing, animation processing. , create community profile lines, create activity storylines, and promotions. The success of the participants can be seen from the results of the training that participants were able to create community profiles and promote IRMAS events, where the level of understanding of participants before training was only 19\% and after training participants' understanding increased to $100 \%$. The activities carried out in this community are very much training to help mass organizations in making digital-based information with a success rate of understanding $81 \%$, this percentage is already above $50 \%$ which is said to be increasing.
\end{abstract}

Keywords: Islamic Youth Association, Kinemaster, Information, Video, Digital

\section{Abstrak}

Aktifitas di dalam masjid tidak hanya melakukan aktifitas ibadah ritual saja, lebih dari itu masjid juga dapat mencetak para remaja tumbuh dalam keimanan, jiwa keorganisasian dan kreatifitas. Salah satu untuk menumbuhkan jiwa keorganisasian para pemuda adalah dengan adanya Ikatan Remaja Masjid (IRMAS). Setiap kegiatan kegiatan IRMAS akan selalu menyiapkan informasi, baik untuk informasi acara maupun informasi informasi kebaikan guna menarik perhatian masyarakat, pemuda maupun remaja untuk mendaparkan pengetahuan, informasi yang diberikan juga dapat menjadi sarana syiar agama dengan mengoptimalakan pada sosial media Instagram dan youtube. Permasalahan dan kendala pada mitra adalah belum memiliki kemampuan dalam membuat informasi berbasis video digital baik untuk membuat profil komunitas, story kegiatan dan media promosi kegiata kegiatan IRMAS serta sarana dakwah yang menarik sehingga sosmed belum bisa dioptimalkan dengan baik. Dengan demikian solusi yang dapat dilakukan dengan melatih keterampilan mitra dalam membuat informasi berbasis video digital dengan aplikasi kine master android dan melatih mengoptimalkan sosial media yang dimiliki sebagai sarana informasi, promosi dan dakwah. Metode yang digunakan dalam pelatihan ini yaitu dengan ceramah dan praktek, dimana peserta pelatihan akan diberikan pemahaman tentang informasi berbasis video digital, cara membuat informasi berbasis video digital dan aplikasi yang digunakan untuk membuat informasi digital, seperti mengolah text, mengolah gambar, mengolah video, mengolah animasi, membuat alur profil komunitas, membuat alur story kegiatan dan alur promosi. Keberhasilan peserta tampak pada hasil pelatihan peserta mampu membuat profil dan promosi acara irmas, dimana tingkat pemahaman peserta sebelum pelatihan hanya $19 \%$ dan setelah dilakukan pelatihan pemahaman peserta meningkat menjadi $100 \%$. Kegiatan pelatihan yang dilakukan pada komunitas ini sanagat membantu irmas dalam membuat informasi berbasis digital dengan keberhasilan tingkat pemahaman sebesar $81 \%$, persentasi ini sudah diatas $50 \%$ dimana ini dinyakatan meningkat.

Kata kunci: Ikatan Remaja Masjid, Kinemaster, Informasi, Video, Digital 


\section{PENDAHULUAN}

Peranan masjid dalam membangun pribadi muslim menjadi sangat penting, karena masjid tidak hanya melakukan aktifitas sholat saja, namun juga bisa dilakukan dengan aktifitas sosial. Dizaman rasulullah saw didalam masjid juga menjadi sarana belajar dan mengajar, mengatur strategi dakwah, pelatihan dan menerima tamu (Zaini, 2016).

Sekretariat Ikatan remaja masjid An nuryahya terletak dijalan Pramuka ujung kelurahan lembah sari dikecamatan Rumbai timur, yang terletak sangat strategis dikelilingi oleh perumahan masyarakat. Ikatan Remaja masjid merupakan bagian dari struktur kecil dalam pengurus masjid yang sangat dibutuhkan dalam regenerasi kepengurusan dimasa yang akan datang. Ikatan remaja masjid yang sering disingkat dengan IRMAS ini beranggotakan para pemuda, remaja, mahasiswa dan siswa yang sangat berperan dalam setiap kegiatan kegiatan masjid (Khasanah et al., 2019), (Fairzah et al., 2014). Kegiatan kegiatan yang biasa dilakukan seperti menyambuat bulan Muharram, Maulid Nabi, Isra walmi'raj maupun kegiatan kegiatan rutin keislaman yang lainnya. Kendala dirasakan pada IRMAS yang belum memahami konsep video digital sebagai sarana informasi yang sanagat diminati oleh pemuda, sehingga anggota irmas kurang kreatif dalam membuat informasi, syiar dan promosi komunitas. Kedua permasalahan pada mitra berkenaan dengan bagaimana membuat informasi berbasis video, karena hal ini sangat membutuhkan kreatifitas seseorang dengan alur pemahaman yang berbeda beda dalam ilmu video editing (Zamsuri et al., 2018). Ketiga peserta mitra belum pernah menggunakan kinemaster sebagai sarana mengolah video, sehinga tidak dapat membuat projek projek informasi yang sangat berguna bagi masyarakat sosmed. Karena itu sangat penting kiranya pelatihan dilakukan pada mitra guna meningkatkan pemahaman dan peningkatan keterampilan peserta guna mendapatkan kebermanfatan pada masyarakat khususnya pada ummat.
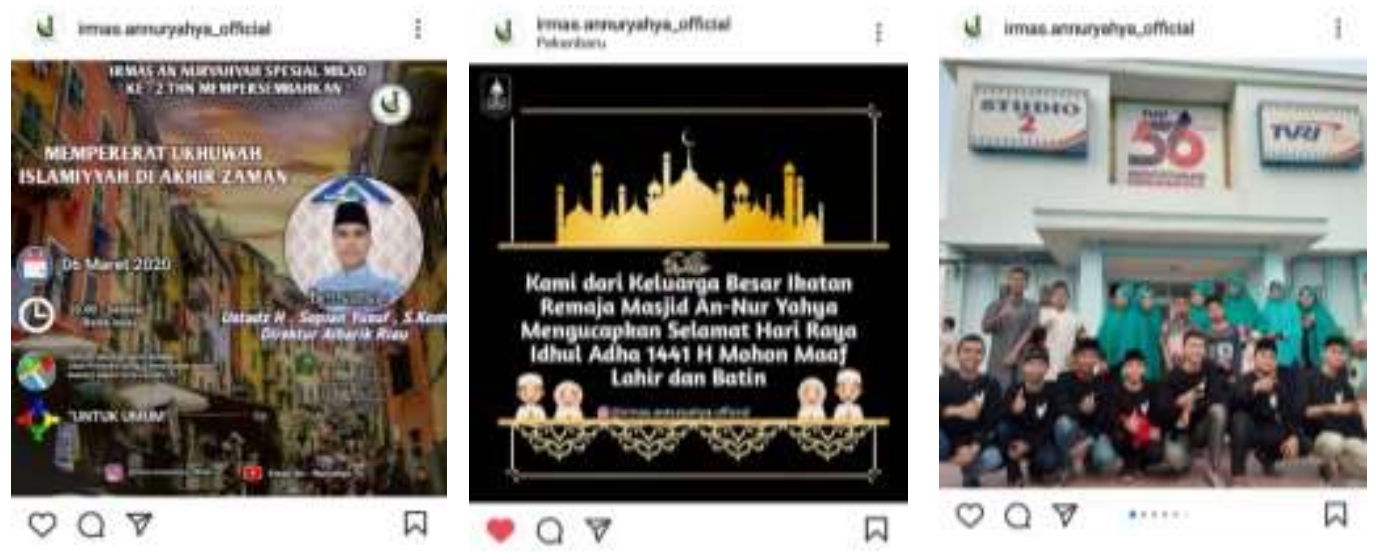

Gambar 1. Informasi IRMAS berbasis text

Dari gambar 1. diatas terlihat dimana setiap informasi, baik promosi undangan, story kegiatan masih berbasis text, sehingga informasi kurang memiliki daya tarik secara visual. Kemudian dari gambar tersebut informasi dakwah belum secara optimal dibuat karena belum memahami keterampilan dalam membuat informasi dakwah yang menarik karena belum adanya sentuhan animasi. Media sosial yang seharus dapat menambah pengetahuan dirasa kurang optimal didapat atau lihat oleh banyak orang sebagai sarana syiar islam.

Salah satu aplikasi yang cukup baik untuk mengolah informasi berbasis video yaitu kinemaster android, dapat mengolah text, mengolah gambar, mengolah video dan mengolah animasi sehingga bisa dipadukan menjadi sebuah objek yang memiliki nilai pengetahuan. Aplikasi kinmaster sudah sangat banyak digunakan untuk kemudahan bagi masyarakat seperti pada penelitian (Haryudin \& Imanullah, 2021) memanfaatkan kinemaster untuk membuat materi ajar berbasis multimedia, (Hasanah et al., 2020) Meningkatkan kemampuan membuat video pembelajaran dengan aplikasi kinemaster di TK Trisua, (Zain et al., 2020) pengembangan media pembelajaran text anetdot, (Nainggolan, 2021) Pengembangan media pembelajaran Matematika 
berbasis video dengan aplikasi kinemaster, (Fajariyah, 2018) pembelajaran text report dengan proyek carding, (Handoko, 2021) Pemanfaatan kinemaster sebagai aplikasi pembuatan iklan video pegi pengelola PKBM, (Khaira, 2020) pemanfaatan aplikasi kinemaster sebagai media pembalajaran bebasis ITC, (Puryono, 2020) pelatihan pembuatan video pembelajaran untuk guru, (Indriani \& R.Pengaribuan, 2020) efektifitas dalam penggunaan media kinemaster terhadap kaum muslimin, (Mahendra \& Minarsih, 2020) tutorial penggunaan aplikasi kinemaster sebagai pengolahan video pembelajaran seni rupa bagi siswa autis.

Berdasarkan uraian diatas yang merupakan hasil justifikasi tim IbM dan calon Mitra, maka didapatkan permasalahan yang dihadapi calon mitra sebagai berikut :

1. Calon mitra belum memahami informasi berbasis video digital

2. Calon mitra tidak mampu membuat informasi berbasis video digital

3. Calon mitra belum pernah menggunakan aplikasi kinemaster

Permasalahan mitra pertama dapat diterangkan dimana media informasi yang sering digunakan oleh mitra yaitu menggunakan aplikasi whatsapp sehingga baik informasi kegiatan dari even even masih menggunakan chat, sehingga kurang manarik untuk dibaca bagi masyarakat generasi $\mathrm{z}$ yang berakibat partisipasi pemuda kurang dalam mengukuti kegiatan kegiatan tersebut. kedua dapat diterangkan bahwa calon mitra belum mampu mengoptimalisasi sosmed sebagai sarana informasi dakwah dan sarana promosi acara hal tersebut tampak like dan tayang yang sangat sedikit.

\section{METODE}

\section{Khalayak Sasaran}

Sasaran kegiatan ini ada anggota ikatan remaja masjid, ketua maupun bagian publikasi dan dokumentasi komunitas.

\section{Prosedur Kerja}

a. Mengusulkan kegiatan Pengabdian Kepada Masyarakat ke LPPM

b. Mengurus dan menyiapkan segala kebutuhan administrasi.

c. Mengirim surat kerjasama untuk melaksanakan kegitatan pengabdian di IRMAS.

d. Menyiapkan modul pelatihan

e. Melakukan sosialisasi dan pelatihan membuat informasi .

f. Melakukan evaluasi terhadap keberhasilan Pengabdian Kepada Masyarakat

Metode Pelaksanaa

Metode pelaksanaan kegiatan pengabdian pada Ikatan Remaja Masjid dapat dilihat bada bagan dibawah ini;

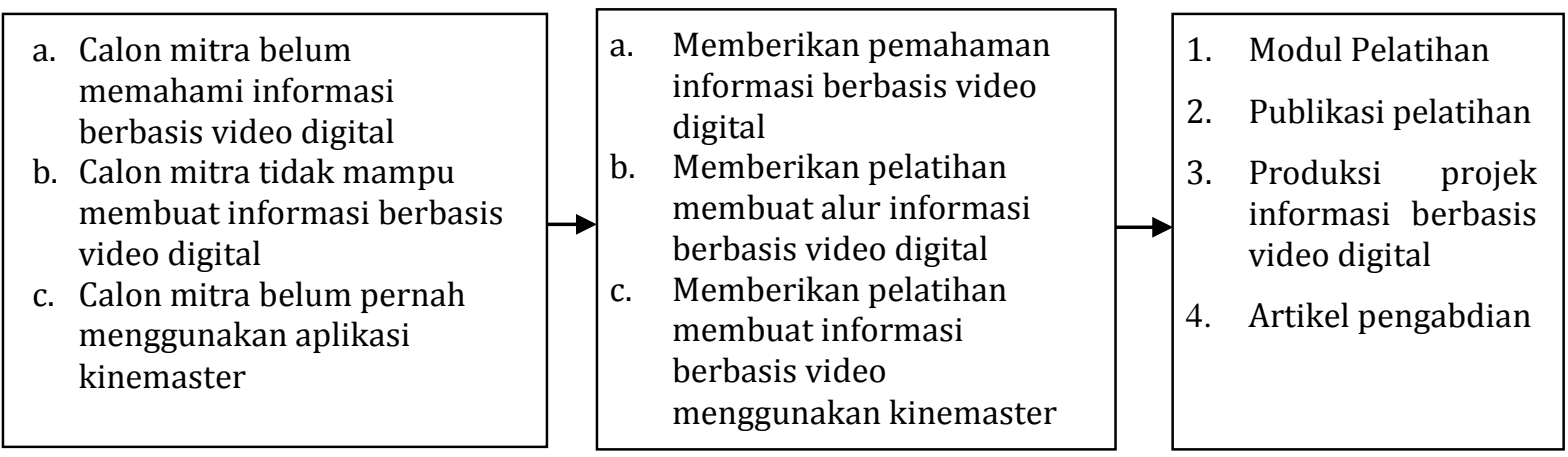

Gambar 2. Metode pemahaman teknologi pelatihan 


\section{HASIL DAN PEMBAHASAN}

Hasil Kegiatan

Pengabdian masyarakat yang dilaksanakan yang dilaksanakan pada ikatan remaja masjid berjalan dengan lancer, sedangkan waktu yang berjalan cukup optimal dalam memahami Langkah demi Langkah materi yang disajikan. Demikian bagaimana cara mengaplikasikan kinemater yang sangat mudah digunakan, setiap fungsi fitur nya juga mudah untuk di olah agar menjadi sebuah projek yang baik, adapun kegiatan kegiatan yang dilakukan dapat dilihat pada gambar berikut ini;

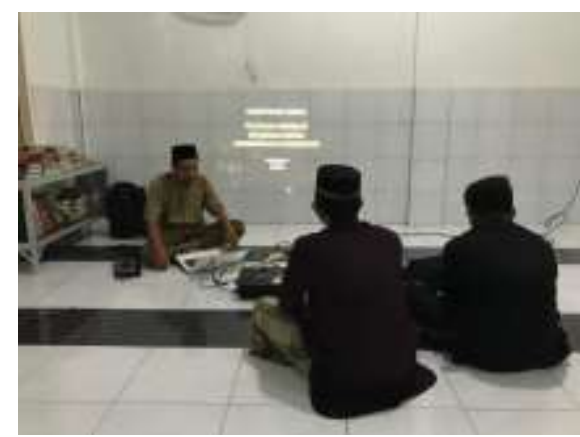

Gambar 3. Pembukaan Pelatihan

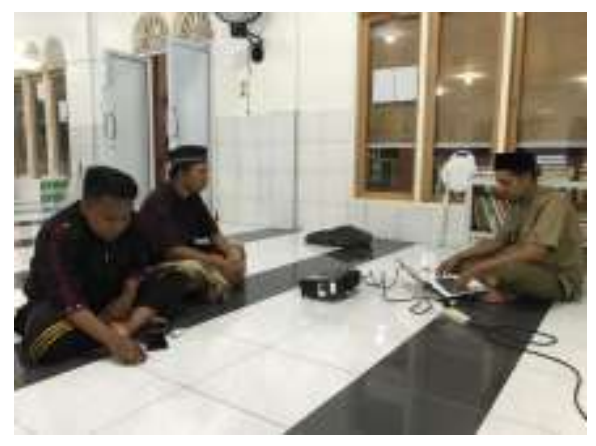

Gambar 4. Alur informasi video digital

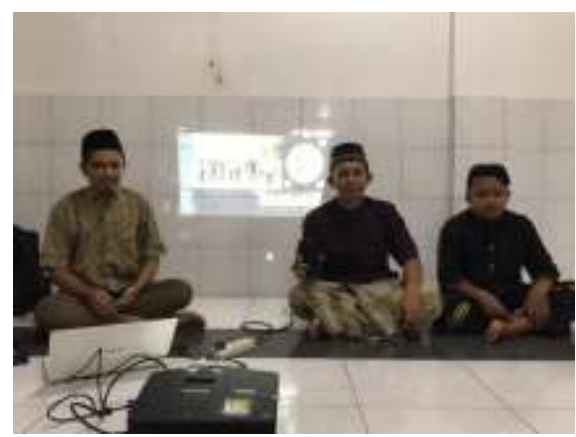

Gambar 5. Peserta praktek membuat projek

Pada gambar 3. Peserta pelatihan mengikuti pelatihan diawali dengan pembukaan dan perkenalan agar peserta memahami langkah demi Langkah pelatihan, pada gambar 4. Intruktur pelatihan memberikan pemahaman berkenaan dengan informasi video digital hal ini agar peserta semakin menjiwai tentang video digital, contoh contoh video digital kemudian hingga praktek membuat informasi berbasis video digital. Adapun salah satu bentuk projek Latihan yaitu membuat informasi profil berbasis video digital yang dapat dilihat sebagai berikut.

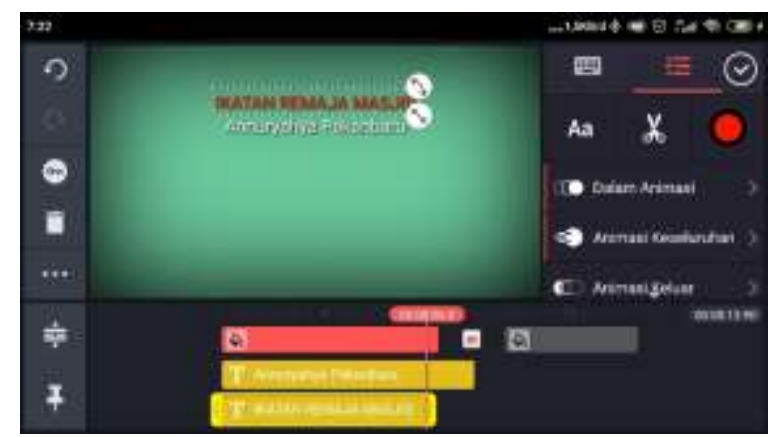

Gambar 6. Tampilan informasi profil IRMAS

Pembahasan

Berikut pembahasan dalam pelatihan yang telah dilakukan selama 7 jam, dengan 3 peserta pelatihan, dengan test pemahaman sebelum pelatihan, kemudian memberikan pelatihan dengan 
modul hingga menjadi sebuah informasi video digital. Diakhir pelatihan tim pengabdian memberikan umpan balik untuk mengetahui peningkatan pemahaman peserta pelatihan dengan instrument quisioner, berikut penjelasanya;

Tabel 1. Presentasi pretest (sebelum pelatihan mendapatkan pemahaman 19\%)

\begin{tabular}{clcc} 
No & Pertanyaan & Pertanyaan (Ya) & \% Pertanyaan (Ya) \\
\hline 1 & K1 & 3 & $100 \%$ \\
2 & K2 & 3 & $100 \%$ \\
3 & K3 & 2 & $67 \%$ \\
4 & K4 & 0 & $0 \%$ \\
5 & K5 & 0 & $0 \%$ \\
6 & K6 & 0 & $0 \%$ \\
7 & K7 & 0 & $0 \%$ \\
8 & K8 & 0 & $0 \%$ \\
9 & K9 & 0 & $0 \%$ \\
10 & K10 & 0 & $0 \%$ \\
11 & K11 & 0 & $0 \%$ \\
12 & K12 & 0 & $0 \%$ \\
13 & K13 & 0 & $0 \%$ \\
14 & K14 & 0 & $0 \%$ \\
Total & 8 & 266,7 \\
Rata rata & 0,6 & 19,0 \\
Tingkat total pengetahuan & & $19,0 \%$ \\
\hline
\end{tabular}

Dengan pengujian secala guttment dimana peserta pelatihan dapat menjawab pertanyaan YA dan TIDAK sebanyak 14 pertanyaan, dimana jawaban YA bernilai 1 dan jawaban TIDAK bernilai 0 maka dapat dilihat persentasi pemahaman peserta sebelum dilaksanakan pelatihan sebesar 19\%. Kesimpulan dari persertasi tersebut bahwa pemahaman peserta masih rendah atau kurang memahami dalam membuat informasi berbasis video digital.

Tabel 2. Presentasi posttest (sesudah pelatihan mendapatkan pemahaman $81 \%$ )

\begin{tabular}{cccc}
\hline No & Pertanyaan & $\begin{array}{c}\text { \% Pertanyaan } \\
(\text { Ya })\end{array}$ & \% Pertanyaan (Ya) \\
\hline 1 & K1 & 3 & 100 \\
2 & K2 & 3 & 100 \\
3 & K3 & 3 & 100 \\
4 & K4 & 3 & 100 \\
5 & K5 & 3 & 100 \\
6 & K6 & 3 & 100 \\
7 & K7 & 3 & 100 \\
8 & K8 & 3 & 100 \\
9 & K8 & 3 & 100 \\
10 & K8 & 3 & 100 \\
11 & K8 & 3 & 100 \\
12 & K8 & 3 & 100 \\
13 & K8 & 3 & 100 \\
14 & K8 & 3 & 100 \\
\hline \multicolumn{2}{l}{ Total } \\
\multicolumn{2}{l}{ Rata rata } \\
\multicolumn{2}{l}{ Tingkat total pengetahuan } & 42 & 1400,0 \\
\hline
\end{tabular}


Pengujian tingkat pemahaman yang sama juga dilakukan setelah selesai dilaksanakan pelatihan dengan jumlah pertanyaan sebanyak 14 pertanyaan dimana peserta memilih antara dua jawaban YA atau Tidak. Hasil pengujian tersebut meningkat, dimana peserta mengalama peningkatan pemahaman dalam pelatihan membuat informasi berbasis video digital dengan perentasi $100 \%$. Kesimpulan nya adalah harapan pelatihan untuk meningkatkan pemahaman peserta berhasil didapatkan.

Selanjutnya jumlah persentasi pengetahuan peserta pelatihan dihitung dengan rumus, Kuisioner $=$ (Nilai rata rata $/$ jumlah kuisioner $) \times$ nilai persentasi $(100 \%)$. Sehingga didapatkan pilihan "YA" 100\% dikarenakan seluruh peserta sangat memahami maksud seluruh (14) butir pertanyaan tersebut, sedangkan untuk peserta tidak memahami maksud 0 butir pertanyaan dengan persentasi $0 \%$. Total persentasi pengetahuan sesudah dilakukan pelatihan didapatkan $100 \%$ dimana hal ini menggambarkan bahwa peserta sudah memahami maksud pelatihan informasi berbasis video digital dengan catatan tetap dibawah pendampingan tim pelaksana. Untuk mengetahui kenaikan pengetahuan peserta dari sebelum mendapatkan pelatihan kemudian dilaksanakannya pelatihan penggunaan aplikasi kinemaster dengan cara,

$\%$ Kenaikan $=$ Jumlah persentasi posttest - Jumlah persentasi preetest

maka dapat diterjemahkan \%: $100 \%-19 \%=81 \%$.

Sehingga dapat dilihat peningkatan pemahaman peserta dalam memahami cara membuat informasi berbasis video digital dengan tingkat kenaikan $81 \%$, dapat dikatakan jumlah persentasi tersebut naik secara signifikan setelah diberi pelatihan kepada peserta. Hasil persentasi dapat dilihat pada gambar 5 berikut ini

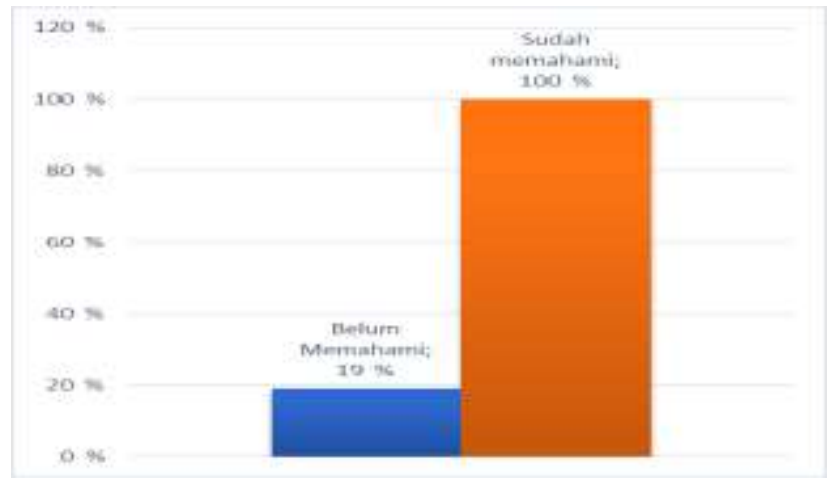

Gambar 7. Hasil perbandingan peningkatan pemahaman peserta

Gambar diatas menerangkan perbandingan tingkat pemahaman peserta dari sebelum dilakukan nya pelatihan dan sesudah dilaksanakannya pelatihan, sebanyak 14 butir pertanyaan diajukan kepada peserta pelatihan guna mengetahui sejauh mana pemahaman peserta pelatihan dalam membuat informasi berbasis video digital. Hasil pengujian peserta pelatihan peserta tingkat pemahaman yang didapatkan $19 \%$ ini dikarenakan peserta hanya mengetahui beberapa pemahaman tentang video digital seperti pernah kah anda mendengar tentang informasi berbasis video namun Ketika pertanyaan berkenaan dengan cara mengolah informasi video dengan kine master perserta belum pernah melakukkanya. Sebaliknya setelah dilakukannya pelatihan pemahaman peserta meningkat dimana menjadi $100 \%$ hal ini dikarenakan peserta mengikuti kegiatan pelatihan dengan baik, mulai dari bagaimana mengolah text, mengolah gambar, mengolah video dan mengolah animasi dengan kinemaster.

\section{KESIMPULAN}

Kesimpulan yang didapatkan dari hasil pengabdian pada ikatan remaja masjid dapat dibahas sebagai berikut; 

a. Bahwa tingkat pemahaman anggota irmas masih rendah tentang membuat aplikasi berbasis video digital sebesar $19 \%$
b. Bahwa tingkat pemahaman peserta meningkat sebesar $100 \%$ setelah mendapatkan pelatihan
c. Bahwa tingkat kenaikan pemahaman pelajar dalam membuat aplikasi sebesar $81 \%$

\section{UCAPAN TERIMA KASIH}

Penulis mengucapkan terima kasih kepada pimpinan Fakultas Teknik dan Ilmu Komputer Universitas Lancang Kuning yang telah memberi dukungan financial terhadap pengabdian ini.

\section{DAFTAR PUSTAKA}

Fairzah, Lubis, Z., \& Fadhil, A. (2014). Upaya Ikatan Remaja Masjid Jami N urul A'la dalam Mencegah Kenakalan Remaja di Jatiluhur Jatiluhur Jatiasih Bekasi Faizah, Zulkifli Lubis, Abdul Fadhil Universias Negeri Jakarta. Studi Al Qur'an, 10(2), 178-188.

Fajariyah, L. A. (2018). Pembelajaran Teks Report Dengan Proyek "Cerdig" Berbasis KineMaster. Jurnal Didaktika Pendidikan Dasar, 2(1), 182-192.

Handoko, A. (2021). Pemanfaatan Kinemaster Sebagai Aplikasi Pembuatan Iklan Video Bagi Pengelola Dan Pendidikan PKBM. Kajian Bidang Penelitian Desain, 1(1), 14-24.

Haryudin, A., \& Imanullah, F. (2021). the Utilization of Kinemaster Applications in the Making of Multimedia Based Teaching Materials for English E-Learning in New Normal (Covid-19).

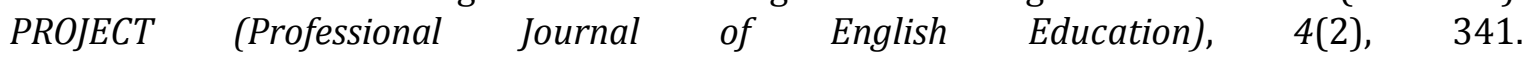
https://doi.org/10.22460/project.v4i2.p341-352

Hasanah, S. U., Anum, A., \& Novalia. (2020). Peningkatan Kemampuan Membuat Video Pembelajaran dengan aplikasi Kinemaster di TK Trisua. Seminar Nasional Dan Pengabian Kepada Masyarakat, 373-376.

Indriani, E., \& R.Pengaribuan, T. (2020). Efektifitas penggunaan media Kinemaster terhadap kemampuan menulis teks prosedur siswa kelas VII SMP Swasta Muhammadiyah 05 Medan.

Khaira, H. (2020). Pemanfaatan Aplikasi Kinemaster Sebagai Media Pembelajaran Berbasis ICT. Prosiding Seminar Nasional, 39-44. http://digilib.unimed.ac.id/id/eprint/41218

Khasanah, W., Umarella, S., \& Lating, A. D. (2019). Peranan Remaja Masjid Ar-Rahman Dalam Pembentukan Karakter Remaja Yang Religius Di Desa Waekasar Kecamatan Waeapo Kabupaten Buru. Kuttab: Jurnal Ilmiah Mahasiswa, 1(1), 57.

Mahendra, I. ketut, \& Minarsih, M. N. M. (2020). Tutorial penggunaan aplikasi Kinemaster sebagai pengolahan video pembelajaran seni rupa bagi siswa autis. Seminar Nasional Seni Dan Desain, 121-126.

Nainggolan, A. C. (2021). Pengembangan Media Pembelajaran Matematika Berbasis Youtube Berbantuan Aplikasi Kinemaster. Journal of Chemical Information and Modeling, 57(1), 254265.

Puryono, D. A. (2020). Pelatihan Pembuatan Video Pembelajaran Untuk Guru Sd Kristen Terang Bagi Bangsa Pati Menggunakan Kinemaster. Jurnal Pengabdian Vokasi, 01(04), 242-247. https://ejournal2.undip.ac.id/index.php/jpv/article/view/8821

Zain, B. M., Wahidah, B., \& M.Ali, N. (2020). Pengembangan Media Pembelajaran text anekdot melalui whatapp dan Facebook, dikelas X SMK Negri. Jurnal Ilmiah Pendidikan Indonesia, 2(1), 45-55.

Zaini, A. (2016). Manajemen Dakwah Ikatan Remaja Masjid Baiturrohman (Irmaba) Di Desa Pucakwangi Kecamatan Pucakwangi Kabupaten Pati. TADBIR: Jurnal Manajemen Dakwah, $1(2), 1-22$.

Zamsuri, A., Syafitri, W., \& As-Syam, F. (2018). Pelatihan Video Editing Di Smp It Madani. Dinamisia: Jurnal Pengabdian Kepada Masyarakat, 2(2), 310-314. https://doi.org/10.31849/dinamisia.v2i2.2984 